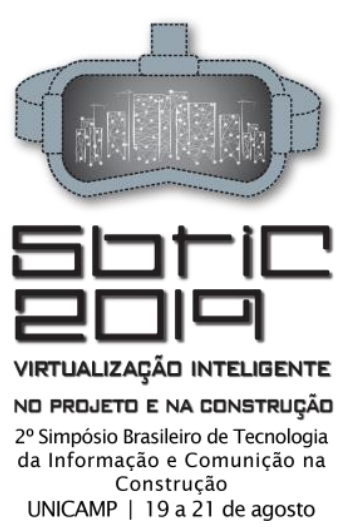

UNICAMP | 19 a 21 de agosto

\section{EYESPACE: PROJETO COLABORATIVO DE UM ÓCULOS PARA PESSOAS COM DEFICIÊNCIA VISUAL NO CENÁRIO INTERNET OF THINGS} Eyespace: Collaborative Project of a Glasses for People
with Visual Impairment in the Internet of Things Scenario

\author{
Sara Rossato De Cesaro \\ Faculdade Meridional IMED | Passo Fundo, RS | saradecesaro@hotmail.com \\ Andrea Quadrado Mussi \\ Faculdade Meridional IMED | Passo Fundo, RS | andrea.mussi@imed.edu.br
}

\section{Luísa Batista de Oliveira Silva}

Faculdade Meridional IMED | Passo Fundo, RS | luisa.projetospredilar@gmail.com

Felipe das Chagas Silva

Centro Universitário Don Domênico | Guarujá, SP | felipe.xagas140@gmail.com

Joicy Carvalho

Centro Universitário Patos de Minas | Patos de Minas, MG | joicyc@unipam.edu.br

\section{Matheus Santos}

Universidade Federal de Uberlândia | Uberlândia, MG |

matheussantos@algartelecom.com.br

\author{
Rishab Nayak \\ Universidade de Boston | Boston, MA | rishab@bu.edu
}

Aditya Narayanan

Universidade de Massachusetts Amherst | Amherst, MA |

aditya.narayanan26@gmail.com

Abhinav Tripathy

Universidade de Massachusetts Amherst | Amherst, MA | abhinavtripathy99@gmail.com

\begin{abstract}
RESUMO
Este artigo apresenta um processo de projeto de pesquisa de iniciação tecnológica e inovação, que se encontra em desenvolvimento. A partir de apresentações em eventos de estímulo à produção tecnológica, foi criada uma rede de trabalho colaborativo a distância entre projetistas e presencial com os usuários do produto desenvolvido. Esse projeto em desenvolvimento é o "Eyespace", um óculos com audiodescrição de imagens para efetiva captura do ambiente construído por pessoas com deficiência visual (PcDV). Inserido na metodologia de projeto colaborativo, este artigo incorpora o óculos Eyespace no cenário Internet of Things (IoT) e os autores como projetistas da revolução 4.0, e disserta sobre esta rede de colaboração que subsidia a produção desse óculos. É demonstrada a importância do projeto colaborativo e da criação desse óculos na vida das PcDV, gerando uma maior autonomia, privacidade e segurança a elas. Os próximos passos da pesquisa são acabar a elaboração do software e hardware, baseados nas necessidades dos usuários, e validar a efetividade do óculos com o mesmo Focus Group referido durante toda a pesquisa.
\end{abstract}

Palavras-chave Óculos; Pessoas com deficiência visual; Internet of things; Projeto colaborativo.

\begin{abstract}
This article presents a process of research project of technological initiation and innovation, which is under development. From presentations at events to stimulate technological production, a collaborative network was created at a distance between designers and face-to-face with users of the developed product. This project in development is the "Eyespace", an glasses with audio description of images to effectively capture the built environment by people with visual impairment (PcDV). Inserted in the methodology of collaborative project, this article incorporates Eyespace glasses into the Internet of Things (IoT) scenario and authors as designers of the 4.0 revolution, and discusses this collaboration network that subsidizes the production of this glasses. It is demonstrated the importance of the collaborative project and the creation of this glasses in the life of the PcDV, generating a greater autonomy, privacy and security to them. The next steps of the research are to finish the development of software and hardware, based on the needs of users, and validate the effectiveness of the glasses with the same Focus Group referred to throughout the research.
\end{abstract}

Keywords Glasses; People with visual impairment; Internet of things; Collaborative project.

CESARO, S.; MUSSI, A.; SILVA, L.; SILVA, F.; CARVALHO, J.; SANTOS, M.; NAYAK, R.; NARAYANAN, A.; TRIPATHY, A. Eyespace: Projeto Colaborativo De Um Óculos Para Pessoas Com Deficiência Visual No Cenário Internet Of Things. In: SIMPÓSIO BRASILEIRO DE TECNOLOGIA DA INFORMAÇÃO E COMUNICAÇÃO NA CONSTRUÇÃO, 2., 2019, Campinas, SP. Anais [...]. Porto Alegre: ANTAC, 2019. Disponível em:

https://antaceventos.net.br/index.php/sbtic/sbtic2019/paper/view/228 


\section{INTRODUÇÃO}

De acordo com a World Health Organization (WHO, 2018), cerca de 1,3 bilhões de pessoas vivem com algum tipo de deficiência visual em todo o mundo. Destas, 217 milhões possuem elevada dificuldade na visão e 36 milhões são cegas. Desta forma, pode-se notar a grande quantidade de pessoas que possuem deficiência visual no mundo e consequentemente não fazem uma efetiva captura do ambiente construído que a elas é exposto regularmente. Grande parte das informações das cidades são visuais, como placas nas ruas e mercadorias no mercado, e muitas ações cotidianas também, como escolher suas roupas, logo essas informações acabam se perdendo em meio a deficiência.

O cenário Internet of Things (IoT) na Indústria 4.0 vem com o intuito de gerar mudanças radicais e novas formas de perceber o mundo através de inovações tecnológicas, destaca Freitas (2017). Sempre buscando inovações que venham suprir as necessidades do público alvo de cada projeto.

Santos et al. (2016) destacam que tem crescido a existência de objetos inteligentes e assim a Internet das Coisas tem cada vez mais conectado esses objetos promovendo comunicações entre usuários e dispositivos. Nesse cenário de comunicações, o Projeto Eyespace propõe óculos, com câmera e fone de ouvido embutidos, com conexão bluetooth a um aplicativo que contém a base de dados necessária para o reconhecimento de imagens e assim audiodescrevê-las às pessoas com deficiência visual, informando objetos, pessoas, roupas e cores a sua frente e fazendo leitura de placas nas ruas.

Portanto, este artigo tem como objeto de estudo o projeto colaborativo e sua importância para a compreensão das necessidades das pessoas com deficiência visual (PcDV) em busca de uma maior independência em locomoções e atividades diárias, assim como ampará-las no processo de inclusão aos ambientes previamente construídos. E de tal modo, o objetivo deste artigo é apresentar o Projeto EyeSpace, no cenário Internet of Things (IoT) com projetistas da revolução 4.0.

\section{METODOLOGIA}

Ideias de alunos do Ensino Superior Brasileiro geraram o Projeto Vivir durante o Hacklab FNESP 2018. Posteriormente através de uma conexão com equipes do Google Cloud foi propiciada a integração de alunos, do Ensino Superior Norte-americano, com ideias semelhantes ao Projeto, o transformando em Projeto Eyespace. E assim conectando mentores do Google Cloud, um grupo norte-americano com ideias semelhantes, a Faculdade Meridional IMED e a Associação Passofundense de Cegos (APACE) esse projeto vem sendo desenvolvido.

Os autores do Projeto Eyespace, quanto a Industria 4.0, incidem como projetistas dessa revolução da nova forma de viver e compreender o mundo, atuando na mudança da rotina do usuário dos óculos propostos por esse projeto. Porém segundo Freitas (2017), as inovações tecnológicas têm avançado velozmente fomentando desenvolvimento de empresas e concorrências, exigindo maior qualidade dos produtos e assim uma melhor compreensão de quais inovações são necessárias para o usuário alvo. Logo, a necessidade do projeto colaborativo como aliado às inovações.

Segundo Carneiro, Barros e Zibel (2011) a participação de usuários na concepção de um projeto, a partir de workshops, possibilita discussões aprofundadas sobre as diferentes necessidades para o projeto. De acordo com suas atividades cotidianas se delimita as possibilidades do projeto e assim são realizadas trocas constantes entre os pesquisadores e usuários para o andamento do projeto.

Imerso na metodologia de projeto colaborativo, a pesquisa desenvolvida neste artigo faz uso de entrevista semiestruturada, passeio acompanhado e Focus Group (Figura 1). 
Figura 1: Projeto Colaborativo.

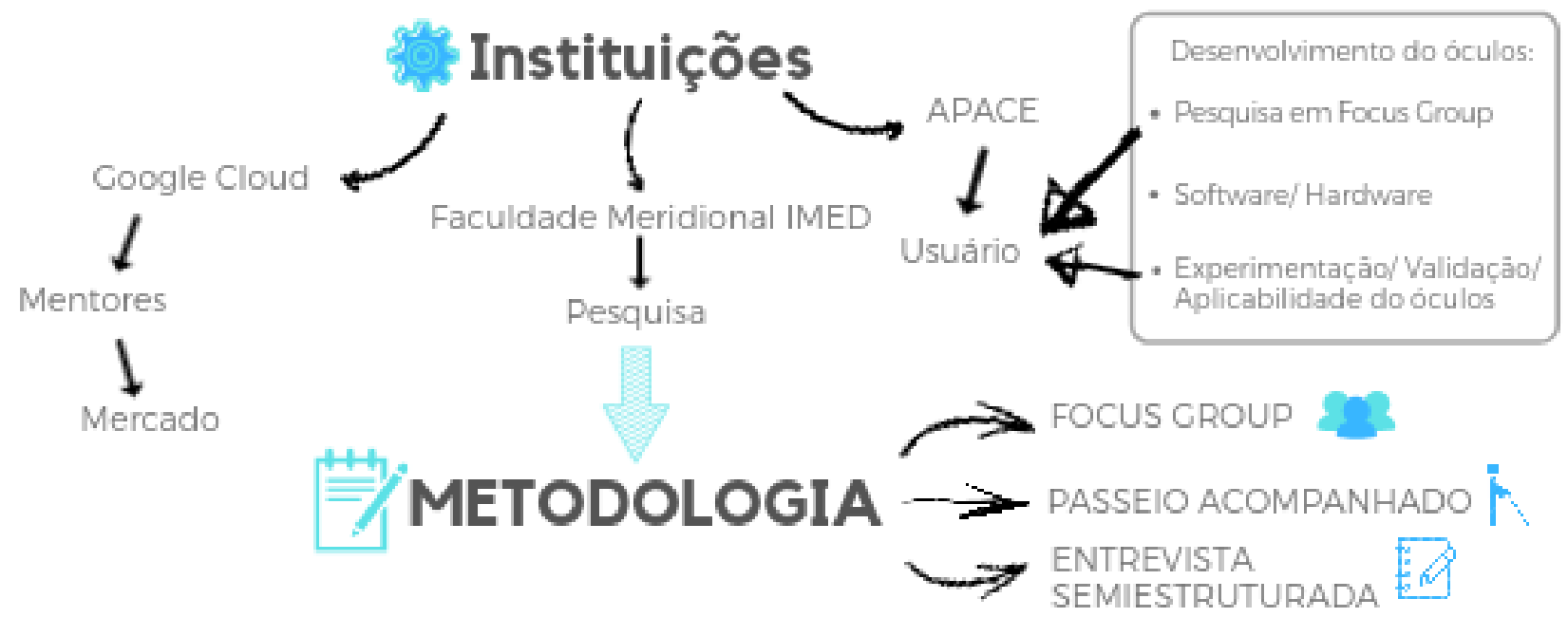

Fonte: Autores (2019).

Até o momento foram realizados dois Focus Group para coleta de dados. Estão incluídos nesse Focus Group seis pessoas associadas da APACE, sendo quatro homens e duas mulheres, todos com idade entre 35 e 55 anos, duas pessoas são cegas e as outras quatro tem baixa visão com graus de visão entre $5 \%$ e $20 \%$. Os Focus Group ocorreram em formato de conversa informal. O primeiro teve como objetivo coletar dados sobre suas dificuldades e facilidades em atividades cotidianas em ambientes externos e internos, sobre suas referências em locomoções sozinhos e algumas questões sobre características para o óculos do projeto em questão neste artigo, já o segundo focou apenas em questões sobre as características prioritárias para o óculos.

Além do Focus Group, foi realizado, com pessoas associadas da APACE, um passeio acompanhado por uma praça, com o foco em analisar a forma como se locomovem em ambientes externos. E em formato de entrevista semiestruturada, foi obtido o feedback de uma pessoa com cegueira total e idade de 13 anos, na presença dos pais, que possui um dispositivo semelhante ao que está sendo criado neste projeto. Entretanto, neste artigo somente será mencionado os resultados do Focus Group.

\section{RESULTADOS}

Em primeiro lugar, o processo da pesquisa a ser analisado são os Focus Group, no qual seis pessoas participaram. No primeiro workshop foram apuradas as seguintes facilidades na vida dos participantes, $66 \%$ deles fazem uso de softwares como DosVox, NVDA, Google TalkBack, entre outros, para auxílio na utilização de notebook e celulares. Enquanto os outros $44 \%$ estão em fase de adaptação a tecnologias. Os pontos de referência utilizados, por $66 \%$ deles, para caminhadas seguras, tanto em ambientes externos quanto internos, são as paredes das construções, o meio-fio, a textura da calçada e os sons. Já as dificuldades cotidianas apuradas, para $100 \%$ dos entrevistados, foram a falta de materiais adaptados, como braile ou ampliações das fontes das letras, não haver a possibilidade de se saber onde está, a não ser decorando por onde foi andado ou perguntando a terceiros, e outras questões visuais que são apenas solucionadas decorando algo pré-concebido ou questionando terceiros. 


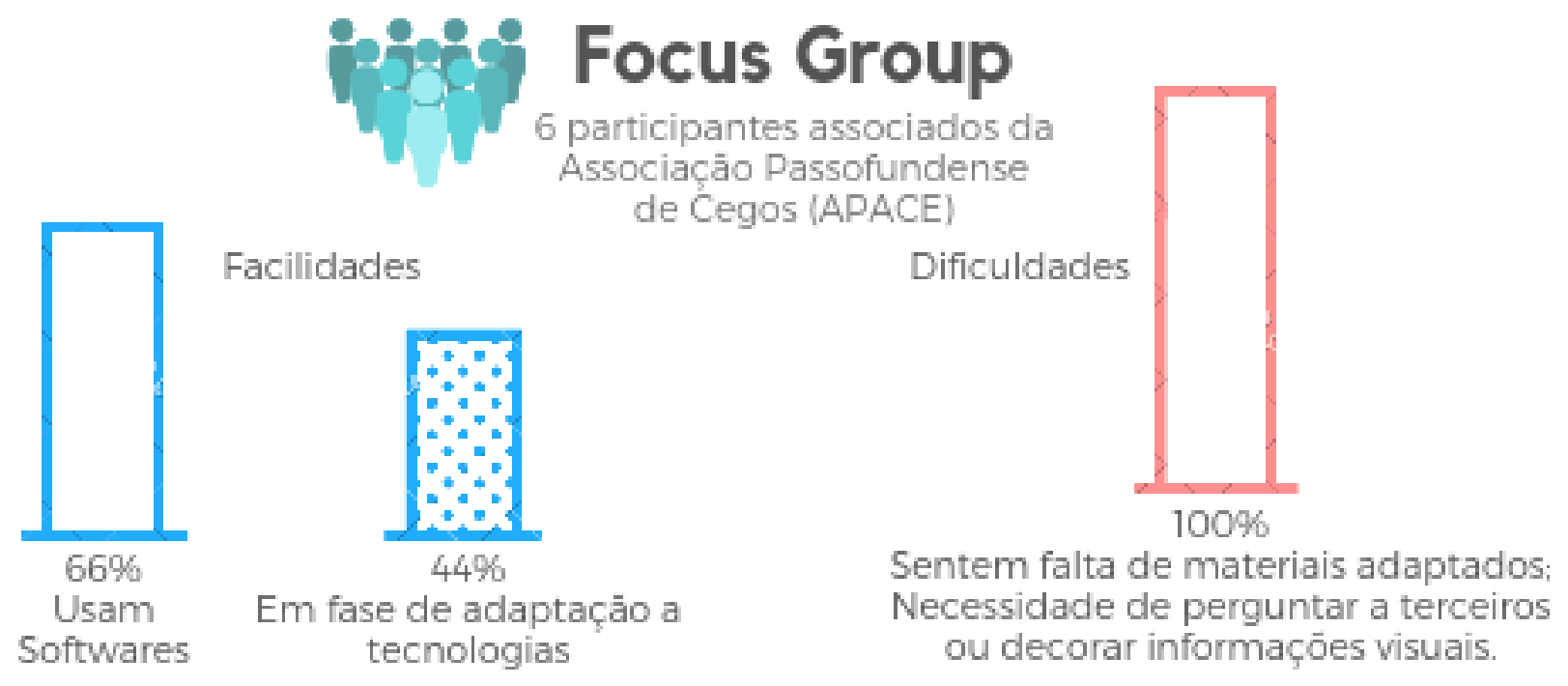

Fonte: Autores (2019).

Os resultados apresentados acima (Figura 2) são do primeiro Focus Group realizado com membros da APACE que colabora na pesquisa, sendo previsto a realização de outras atividades até que se valide todas as informações.

Quanto as prioridades para as características dos óculos, foram coletados os dados no segundo Focus Group. As características mais importantes, para 100\% do grupo, seriam o reconhecimento dos itinerários dos ônibus, o reconhecimento de modelos e cores das roupas, a leitura de preços de mercadorias no mercado e a possibilidade de um GPS poder comunicar onde encontram-se nas ruas e como ir para algum lugar solicitando aos óculos.

Assim analisando os dados, os maiores impasses encontrados pelas pessoas com deficiência visual é a necessidade de sempre estar próximo a um terceiro para questionar algo visual do cotidiano. Com o uso dos óculos EyeSpace, haveria uma maior independência das PcDV com relação a essa dificuldade.

Ao verificar as palavras mais repetidas durante as reuniões do Focus Group, a partir da transcrição das mesmas, foi concluído que "ônibus" foi falado 26 vezes, "bengala" 25 vezes, "autonomia" 21 vezes e "óculos" 20 vezes, sendo os assuntos que mais geraram discussão e que houve maior necessidade de serem ditos pelas PcDV.

Após analisar os Focus Groups realizados, foi possível recolher informações sobre prioridades para implantação nos óculos. O qual terá funcionalidades que estarão ligadas a um aplicativo instalado no celular do usuário, como o reconhecimento do que é exposto a câmera para a posterior áudiodescrição do que está sendo visualizado, e uma assistente virtual para o usuário conversar e perguntar sua localização.

Os passos seguintes são o termino do desenvolvimento do aplicativo e óculos, e então a realização de testes de aplicabilidade com associados da Associação Passofundense de Cegos, os quais colaboraram durante os Focus Groups. O teste ocorrerá com foco em análise do layout do aplicativo e óculos e efetividade do seu uso em uma locomoção em ambiente externo.

\section{DISCUSSÃO}

O desenvolvimento dessa pesquisa trouxe a seguinte reflexão à tona, as informações visuais contidas, principalmente, nos objetos e nas ruas são carecidas de compreensão das PcDV e dificultam sua locomoção independente. Essa compreensão é apenas obtida com a ajuda de terceiros. Lahav e Mioduser (2004) destacam a importância da necessidade de compreensão dos espaços por PcDV, pois isto se torna essencial para um efetivo desenvolvimento da orientação e mobilidade destas pessoas. 
A partir da criação efetiva dos óculos EyeSpace essa compreensão, e consequentemente o uso dos espaços construídos, seria mais eficiente e assim trabalharia a inclusão e independência das PcDV dentro de novas tecnologias e inovações.

\section{AGRADECIMENTOS}

Agradecemos a Faculdade Meridional IMED e a Associação Passofundense de Cegos (APACE) pelo apoio recebido a essa pesquisa.

\section{REFERÊNCIAS}

CARNEIRO, G.; BARROS, G.; ZIBEL, C. Design colaborativo de comportamentos para ambientes interativos. V!RUS, São Carlos, n. 6, dezembro 2011. Disponível em: <http://www.nomads.usp.br/virus/virus06/?sec=4\&item=8\&lang=pt>. Acesso em: 16 fev. 2019.

FREITAS, Arnold de Araujo. A internet das coisas e seus efeitos na indústria 4.0. 2017. 57 f. TCC (Graduação) Curso de Tecnologia em Sistemas de Computação, Universidade Federal Fluminense, Niterói, 2017. Disponível em: <https://app.uff.br/riuff/handle/1/5626>. Acesso em: 08 mar. 2017.

LAHAV, Orly; MIODUSER, David. Blind persons' acquisition of spatial cognitive mapping and orientation skills supported by virtual environment. International Journal On Disability And Human Development, [s.I.], v. 4, n. 3, p.131-138, jan. 2005. Walter de Gruyter GmbH. http://dx.doi.org/10.1515/ijdhd.2005.4.3.231.

Santos, B. P., Silva, L. A., Celes, C. S., Borges, J. B., Neto, B. S. P., Vieira, M. A. M., Vieira, L. F. M., Goussevskaia, O. N. e Loureiro, A. A. (2016). Internet das coisas: da teoria à prática. p. 1-50.

WHO - World Health Organization. Blindness and visual impairment. 2018, Retrieved from:

<http://www.who.int/news-room/fact-sheets/detail/blindness-and-visual-impairment>. Acesso em: 15 fev. 2019. 